\title{
Equine exercise physiology: a challenge for the twenty first century
}

C A Roberts

University of Cambridge, Cambridge, United Kingdom

Email:car43@cam.ac.uk

The study of equine exercise physiology blossomed in the late twentieth century but we must not suppose that it is an entirely new science. As long ago as 1350 B.C., the Hittite Kikkuli text described methods of training horses reminiscent of interval training (McMiken 1990) and more recently the use of a treadmill for the measurement of equine respiration during exercise was reported in 1898 by Zuntz and Hagemann (Hörnicke et al. 1983). Gait analysis too, has a relatively long history. In the nineteenth century, Ellenberger used bells attached to the limbs of galloping horses to record footfall, Marey used pneumatic accelerometers to study gait and Muybridge recorded equine locomotion using a series of cameras (Barrey 1999). In the late twentieth century, a number of technological developments, for example, the high speed treadmill and the force plate, permitted great progress in a number of branches of equine exercise physiology, furthering our understanding of the responses of the horse during exercise and sometimes questioning some of our long held views on the way in which we should manage competition horses.

A challenge for exercise physiologists in the twenty first century is to define suitable research aims. It was stated a few years ago that, 'Unfortunately, at this time the elusive test to predict the future performance of the young and unproven horse does not exist' (Hendrickson 1996), I would contend that such a test is highly undesirable as it would likely result in the best horses being bought by a few wealthy owners reducing opportunities for others. Rather than attempting to improve our ability to predict performance, I suggest that the prime objective of equine exercise physiology should be to improve the welfare of competition horses.

Equine safety and welfare in equestrian competition has advanced considerably but there is still great room for improvement. For example, in National Hunt racehorses, injuries or medical events were reported to occur in $2.88 \%$ of starts (Pinchbeck et al 2004), tendon and suspensory ligament injuries being frequent and in younger, flat racehorses, Verheyen and Wood (2004) found an incidence of nontraumatic fractures of 1.15/100 horse months; $78 \%$ of fractures occurred during training rather than racing. Numerous studies have demonstrated the high prevalence of gastric ulceration in competition horses (see, for example, Jonsson and Egenvall 2006).

Serrano et al. (2002) suggested that many eventing horses are not appropriately trained. A high proportion of athletic injuries in the horse occur to the skeletal system and may frequently arise from a mismatch between the exercise levels and training adaptation (Smith and Goodship 2008). There is evidence that quality and quantity of exercise in the young horse may have an important effect on later susceptibility to injuries (Firth 2006). We should aim to determine optimal methods of training to reduce the predisposition to injury of competition horses, investigate ways in which equestrian sports can be conducted to minimise the risk of injury, and attempt to develop better methods for the sub-clinical diagnosis of competition-related disorders at an early stage.

\section{References}

Barrey, E. 1999. Veterinary Journal 157, 7-22.

Firth, E.C. 2006 Journal of Anatomy 208, 513-26.

Hendrickson. 1996. Veterinary Clinics of North America Equine Practice 12, 607-12.

Hörnicke, H., Meixner, R. and Pollmann, U. 1983 Equine Exercise Physiology. Granta, Cambridge. 7-16.

Jonsson and Egenvall. 2006 Equine Veterinary Journal 38, 209-213.

McMiken, D.F. 1990. Equine Veterinary Journal 22, 73-8.

Pinchbeck, G.L., Clegg, P.D., Proudman, C.J., Stirk, A., Morgan, K.L. and French, N.P. 2004. Vet Journal 167, 45-52.

Serrano, M.G., Evans, D.L. and Hodgson, J.L. 2002 Equine Veterinary Journal Supplement 34, 135-9.

Smith, R.K. and Goodship, A.E. 2008. Veterinary Clinics of North America Equine Practice 24, 37-51.

Verheyen, K.L. and Wood, J.L. 2004. Equine Veterinary Journal 36, $167-73$. 